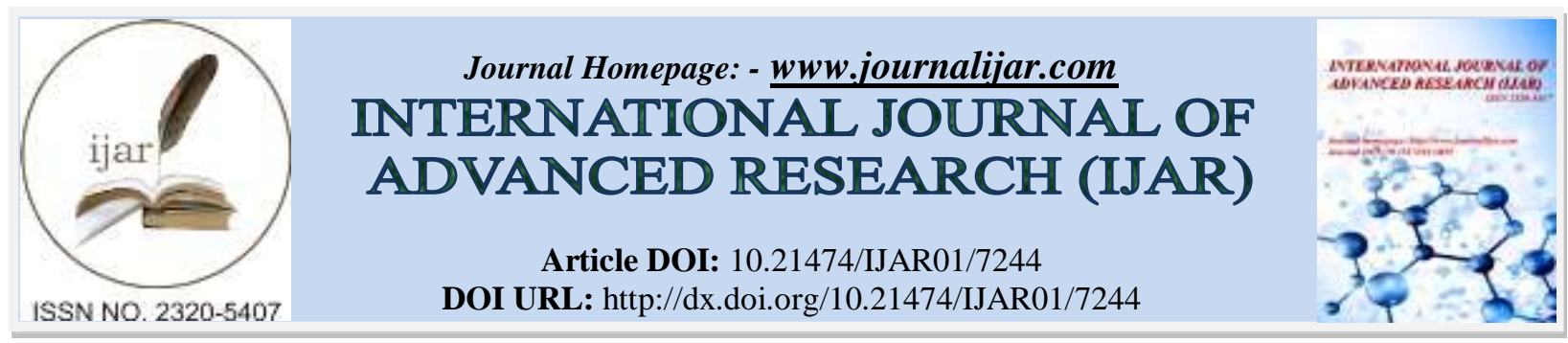

RESEARCH ARTICLE

\title{
EFFICACY OF PLANT EXTRACT, EMBLICA OFFICINALIS IN REMEDIATION OF MALACHITE GREEN INDUCED DEMEANOR ALTERATIONS IN CYPRINUS CARPIO.
}

Reshma Sinha and Rajinder Jindal.

Aquatic Biology Laboratory, Department of Zoology, Panjab University, Chandigarh -160 014.

\section{Manuscript Info}

Manuscript History

Received: 09 April 2018

Final Accepted: 11 May 2018

Published: June 2018

Keywords:-

Emblica officinalis, malachite green, Cyprinus carpio, chronic toxicity, behaviour.

\begin{abstract}
Traditionally Emblica officinalis is an effective medicine in ayurvedic system to treat various diseases and hepatic ailments. Malachite green (MG) is a dye, extensively used in textile, paper, leather and confectionary industry. Effectiveness as aquaculture therapeutant, contribute to its addition in list of aquatic toxicant. Semi static bioassay was maintained to assess the efficacy of Emblica officinalis extract as ameliorant in malachite green induced toxicity in Cyprinus carpio. Toxicological investigation comprised of study of alterations in fish demeanor such as opercular movements, air gulping and fin movements (dorsal and caudal) after chronic exposure to malachite green and its restorations on oral supplementation (feed) of plant extract of Emblica officinalis. Observations revealed increased opercular movements \& air gulping and reduced fin movements on exposure to dye. However on supplementation with $E$. officinalis extract behavioural activities were restored near to control fish. From the present investigation it can be concluded that E. officinalis possess potential to restore the altered behavioural activities in $C$. carpio exposed to sublethal concentration of MG, suggesting efficacy of E. officinalis in combating fish stress against toxicants.
\end{abstract}

Copy Right, IJAR, 2018,. All rights reserved.

\section{Introduction:-}

Plants and its extract form the basis of ayurvedic system of medicine. Plant have been known since ancient times for its antioxidative, antibacterial, antiseptic and anti helminthic efficacy due to the phytochemical constituents present in them. Emblica officinalis, is a historical plant used since ancient times against various ailments, by virtue of its active bioingredient such as flavonoids, gallic acid and vitamin C (Yokozawa et al., 2007). Malachite green is actively used in many developing countries (Sandra et al., 1999), even it is banned in many European countries, considering its carcinogenic, mutagenic, bioaccumulative, genotoxic properties. Its reported use in aquaculture as an effective therapeutant, against Icthyophthirius and Saprolegniasis, make it an inevitable aquaculture toxicant.

Studies have revealed MG contamination in fish exposed to it, even after months making it unfit for human consumption. Persistence of dye is by its reduction into colourless leuco form, leuco malachite green (LMG), with even higher reported toxicity (Hidayah et al., 2013) and half life (Mitrowska et al., 2007). Fish are sensitive organism and serve as sentinel for the ecotoxicity assessment. Furthermore these also form important constituent of aquaculture thus serve as an experimendal model for toxicity bioassay. 
Behaviour is reflection of inner health and indicates any change occurring in body. It links physiology and ecology of an organism with its environment. Behaviour is both quantitative and qualitative aspect. It depicts actions at central and peripheral nervous systems and the cumulative manifestation of genetic, biochemical and physiological processes essential for living such as feeding, reproduction and predator avoidance. During present study, observations were made on any change in behavioural aspects like opercular movements, fin movements and air gulps when exposed to malachite green and E. officinalis extract.

\section{Materials and methods:-}

Malachite green oxalate (90\% pure), triaryl methane dye was obtained from CDH chemicals, New Delhi. Healthy fingerlings of Cyprinus carpio $(13 \pm 2.11 \mathrm{~cm}$ and $15 \pm 2.03 \mathrm{gm})$ were procured from Sultan Singh fish seed farm, Karnal, Haryana. Fish were brought in oxygenated polythene bags and transferred to glass aquarium well fitted with filters and aerators. Semi static assay was carried in $65 \mathrm{~L}(650 \times 320 \times 340 \mathrm{~mm})$ non toxic plastic sintex tanks. Water was renewed after every $24 \mathrm{~h}$ to maintain the concentration of malachite green and to remove the bio-waste. Experimental assay was conducted following the guidelines of APHA (2012). $96 \mathrm{~h} \mathrm{LC}_{50}$ was determined by Probit analysis (Finney, 1980) on the basis of percentage mortality. Four groups were maintained, group I- control, group II- MG, group III- E. officinalis and group IV- MG + E. officinalis. Fish were exposed to $0.146 \mathrm{mg} / \mathrm{L}$ of MG as sublethal concentration $\left(1 / 3^{\text {rd }}\right.$ of $\left.96 \mathrm{~h} \mathrm{LC}_{50}\right)$ for 15,30 and 60 day. Emblica fruits were procured from university campus and ethanolic extract was prepared by Soxhlet extraction method. Feed was prepared by adding $1000 \mathrm{mg} / \mathrm{kg}$ E. officinalis extract in commercially available fish feed (Toya). Behavioural aspects were evaluated by observing fish $(n=6)$ after each exposure period in all groups for 5 minutes.

\section{Statistical analysis:-}

Analysis of variance (ANOVA) followed by Tukeys multiple comparisons test was employed to compare mean differences in between the control and different exposure groups. All statistical test were performed using SPSS 18 and statistical significance $(\mathrm{p}<0.05)$ was considered.

\section{Results and discussion:-}

Chronic toxicity bioassay showed significant effect of both the toxicant and plant extract exposure on fish behaviour (Fig. 1).

\section{Opercular movements}

Toxicity bioassay revealed significant $(\mathrm{p}<0.05)$ increase in fish opercular movement by $66.2 \%$ after 15 day exposure, while it has fallen down to $49.27 \%\left(30^{\text {th }} \mathrm{d}\right.$ ) with subsequent lowering by $27.66 \%$ on $60^{\text {th }}$ day as compared to control. Whereas E. officinalis only fed fish, showed insignificant change $(1.57 \%, 9.26 \%$ and $10.80 \%)$ after 15 , 30 and 60 day exposure as compared to control. Group IV with E. officinalis supplementation in malachite green stressed fish, depicted significant change by $47.73 \%\left(30^{\text {th }}\right.$ day $)$ and $21.57 \%\left(60^{\text {th }}\right.$ day) as compared to toxicated group. Srivastava et al. (1995) reported increased opercular movements in malachite green exposed Heteropneustes fossilis. As observed during ( $30 \& 60 \mathrm{~d}$ ) exposure, the decrease in opercular movement has also been noticed in other fishes on exposure to pesticides (Okechukwu et al., 2013; Sinhorin et al., 2014).

\section{Fins movements}

Dorsal fin movement is related with the equilibrium and balance maintained by the fish and caudal fin movement acts as steering. Dorsal fin movements have been found to be decreased to $29.27 \%$ (15d), $44.19 \%$ (30d) and $70.71 \%$ (60d) as compared to control. Whereas, amelioration group revealed non-significant recovery till 30 day, while significant attenuation was observed after 60 day supplementation, indicating need of extended feeding period requirement for the recovery.

Similar declining trend has been observed in caudal fin movements. It showed insignificant $(\mathrm{p}<0.05)$ decrease by $30.59 \%$ on 15 th day, $35.70 \%$ on 30th day on exposure to malachite green at $0.146 \mathrm{mg} / \mathrm{l}$, while similar insignificant changes was observed at these periods. Chronic exposure (60 d) to dye resulted in significant decrease by $47.94 \%$ as compared to control; while $38.18 \%$ amelioration was observed with respect to MG intoxication, signifying attenuating efficacy of the E. officinalis extract. It has been noticed that after prolonged exposure, the fish became sluggish and swimming activity decreased to a marked level and they escaped in the corners of the experimental tanks. Sluggishness, loss of equilibrium and abnormal swimming movements has also been reported by other workers (Srivastava et al., 2004, Jin et al., 2015). 


\section{Air gulping}

Air gulping at the surface of the water is an abnormal behaviour and is indicative of severe hypoxia. The hypoxia is a state of distress and may show an escaping tendency from water. During present investigation, on exposure of the fish to the toxicant for initial days, caused insignificant increase, however continued exposure resulted in significant ( $\mathrm{p}<0.05$ ) elevation by $132.42 \%$ (30 day) and $255.98 \%$ (60 day) in air gulping compared to control. Attenuating effect of E. officinalis was observed with significant change by $70.89 \%$ and $41.32 \%$ with respect to toxicant after 30 and 60 day respectively. Indicating extended exposure period requirement for amelioration effect. The enhanced air gulping can be attributed to the hypoxic condition created by the dye, thus the fish come up to the surface to engulf air bubbles from dissolved oxygen saturated water layer. The increased surfacing and air gulping under the stress created by the toxicants has been reported in Labeo rohita on exposure to malathion by Patil and David (2008). Similar observations have been recorded by Bhat et al. (2012) and Singh et al. (2010).

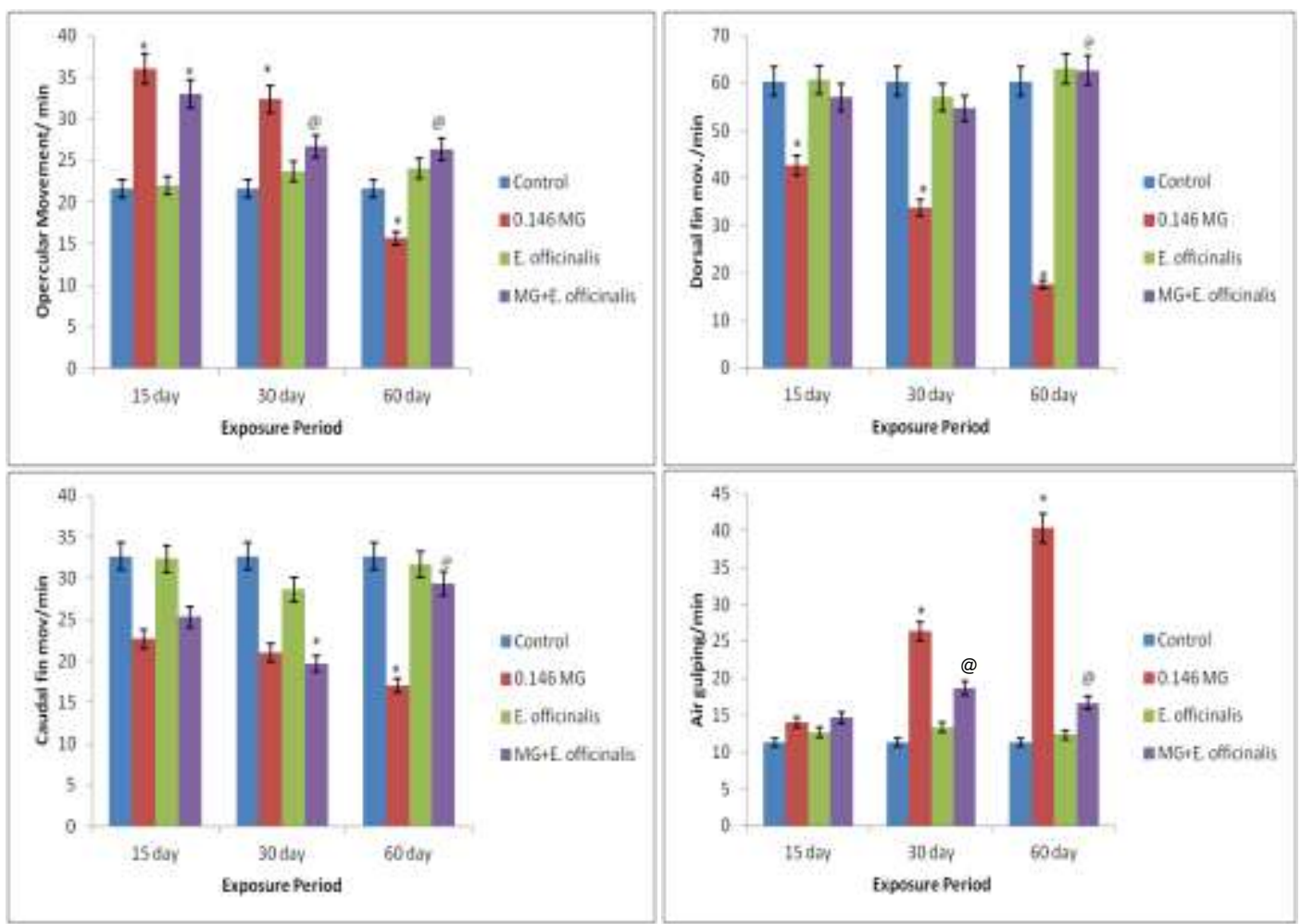

Fig. 1:- Variations in behavioural pattern in response to malachite green and Emblica officinalis in Cyprinus carpio.

Results are significant at $\mathrm{p}<0.05$; $*$ indicates significant change compared to control; @ indicates significant change compared to respective MG treatment.

\section{Conclusion:-}

On account of the observations made, it could be concluded that Emblica officinalis supplementation does not possess any change, instead maintained fish health, thus relying its use in fish. Furthermore, it showed effectiveness against stress developed by toxicant in Cyprinus carpio. Thus it can be considered as diet supplement in fish inhabiting contaminated water. 


\section{References:-}

1. APHA (2012). Standard Method for the Examination of Water and Waste Water. 22nd ed. American Public Health Association, Washington, D.C.

2. Bhat, I.A., Bhat, B.A., Vishwakarma, S., Verma, A. and Saxena, S. (2012). Acute toxicity and behavioural responses of Labeo rohita (Hamilton) to a biopesticide Neem-on. Current World Environment, 7(1): $175-178$.

3. Finney, D.J. (1980). Probit Analysis, 3rd edn. Cambridge Univ. Press, London and New York.

4. Hidayah, N., Abu Bakar, F., Mahyudin, N.A., Faridah, S., Nur-Azura, M.S. and Zaman, M.Z. (2013). Detection of malachite green and leuco-malachite green in fishery industry. International Food Research Journal, 20(4): 1511-1519.

5. Jin, Y., Liu, Z., Peng, T. and Fu, Z. (2015). The toxicity of chlorpyrifos on the early life stage of zebrafish: A survey on the endpoints at development, locomotor behavior, oxidative stress and immunotoxicity. Fish and Shellfish Immunology, 43(2): 405-414.

6. Mitrowska, K., Posyniak, A. and Zmudzki, J. (2007). The effects of cooking on residues of malachite green and leuco-malachite green in carp muscles. Analytica Chimica Acta, 586: 420-425.

7. Okechukwu, O.E., Usman, I.B. and Jehu, A. (2013). Investigation of acute toxicity of chlorpyrifos-ethyl on Clarias gariepinus (Burchell, 1822) using some behavioural indices. International Journal of Basic and Applied Sciences, 2(2): 176-183.

8. Patil, V.K. and David, M. (2008). Behaviour and respiratory dysfunction as an index of malathion toxicity in the freshwater fish, Labeo rohita (Ham.). Turkish Journal of Fisheries and Aquatic Sciences, 8: 233-237.

9. Sandra, J.C., Lonnie, R.B., Donna, F.K., Daniel, R.D., Louis, T.M. and Frederick,A.B. (1999).Toxicity and metabolism of malachite green and leucomalachite green during short-term feeding to Fisher 344 rats and B6C3F, mice. Chemico- Biological Interactions, 122: 170-253.

10. Singh, R.N., Pandey, P.K., Singh, N.N. and Dass, V.K. (2010). Acute toxicity and behavioral responses of common carp Cyprinus carprio (Linn.) to an organophosphate (dimethoate). World Journal of Zoology, 5 (3): 183-188.

11. Sinhorin, V.D.G., Sinhorin, A.P., Teixeira, J.M.S., Mileski, K.M.L., Hansen, P.C., Paulo Rafael Moeller, P.F., Moreira, P.S.A., Baviera, A.M. and Loro, V.L. (2014). Metabolic and behavior changes in surubim acutely exposed to a glyphosate-based herbicide. Archives of Environmental Contamination and Toxicology, 67: 659667.

12. Srivastava, A.K., Sinha, R., Singh, N.D., Roy, D. and Srivastava, S.J. (1995). Malachite green induced changes in carbohydrate metabolism and blood chloride levels in the freshwater catfish, Heteropneustes fossilis. Acta Hydrobiologica, 37:113-119.

13. Srivastava, S., Sinha, R. and Roya, D. (2004) Toxicological effects of malachite green. Aquatic Toxicology, 66:319-329.

14. Yokozawa, T., Kim, Y.H., Kim, J.H., Tanaka, T., Sugino, H., Okubo, T., Chichu, D. and Juneja, R.L. (2007). Amla (Emblica officinalis Gaertn) attenuates age related renal dysfunction by oxidative stress. Journal of Agricultural and Food Chemistry, 55: 7744-7752. 